\title{
20 anos estabelecendo parcerias em prol do turismo
}

Roberto Bartholo

Universidade Federal do Rio de Janeiro (UFRJ), Brasil periodicocvt@gmail.com

\section{Eloise Silveira Botelho}

Universidade Federal do Estado do Rio de Janeiro

(UNIRIO), Brasil

eloise.botelho@unirio.br

Aguinaldo Cesar Fratucci

Universidade Federal Fluminense (UFF), Brasil

acfratucci@gmail.com

Camila Gonçalves de Oliveira Rodrigues

Universidade Federal Rural do Rio de Janeiro (UFRRJ),

Brasil

camirural@gmail.com

Ivan Bursztyn

Universidade Federal do Rio de Janeiro (UFRJ), Brasil

ivan.bursztyn@gmail.com

Flavia Ferreira Mattos

Universidade Federal do Rio de Janeiro (UFRJ), Brasil

flaviamattosbr@gmail.com

Edney Sacnhez

Universidade Federal do Rio de Janeiro (UFRJ), Brasil

ectsanchez@gmail.com

Fernanda Tavares Barcelos

Universidade Federal do Rio de Janeiro (UFRJ), Brasil

ftbarcelos@gmail.com
DOI: https://doi.org/10.18472/cvt.21n3.2021.1855

Redalyc: https://www.redalyc.org/articulo.oa? id $=115469516012$

Em 2021, o CVT completa 20 anos de sua primeira edição. Essa trajetória que tanto nos orgulha não seria possível sem as inúmeras parcerias que apoiaram a consolidação desse importante veículo de comunicação científica para o campo do Turismo.

Quando idealizamos o CVT, o cenário da pesquisa em Turismo era muito diferente do que encontramos hoje. Em especial no estado do Rio de Janeiro, não havia cursos de graduação e pós-graduação em turismo em instituições públicas de ensino superior e a produção científica do campo estava dispersa em muitos programas de pós-graduação que tinham no Turismo um campo ainda pouco explorado para suas pesquisas.

O CVT nasce como uma ação vinculada ao Instituto Virtual de Turismo, projeto de pesquisa financiado pela Fundação de Amparo a Pesquisa do Estado do Rio de Janeiro (FAPERJ). O projeto reuniu pesquisadores de diferentes instituiçóes do estado cujo foco principal de suas atuações fosse os estudos em turismo. 
Mapeamos e provocamos interações com dezenas de pesquisadores para que contribuíssem para a existência do periódico, seja como autores, avaliadores ou mesmo como leitores.

Podemos dizer que o CVT é contemporâneo da internet. Sua proposta inicial já foi pensada tendo a grande rede como suporte. $\mathrm{Na}$ ocasião intuíamos o potencial de difusão dos conhecimentos provocados pela novidade e não faria sentido iniciar essa jornada tendo como suporte materiais impressos. O CVT é virtual desde sua origem. É gratuito, de acesso livre a todos. Nunca cobramos de autores nem de leitores para acessarem o conteúdo publicado, não porque tínhamos garantidos os meios para viabilizar sua produção, mas por acreditarmos que o conhecimento deve ser livre e acessível a todos os interessados.

Fomos um dos primeiros periódicos brasileiros a implementar o Sistema Eletrônico de Editoração de Revistas (SEER), software adaptado do internacional Open Journal System (OJS) pelo Instituto Brasileiro de Informação em Ciência e Tecnologia (IBICT). E nossa plataforma foi utilizada como referência em cursos de capacitação oferecidos pelo IBICT para editores de todo o Brasil devido às inovações em termos de layout que tivemos o cuidado de oferecer aos nossos leitores. Dentre os periódicos do campo do Turismo, fomos pioneiros em disponibilizar todo nosso conteúdo em versão digital. Nosso empenho em oferecer um ambiente virtual inovador não seria possível sem a parceria e colaboração dos inúmeros desenvolvedores que tornaram a versão brasileira do OJS uma realidade.

Cada edição publicada representava o esforço de uma equipe multidisciplinar de pesquisadores que dispunham seus conhecimentos e habilidades técnicas de revisão, normatização e diagramação para consolidar uma estratégia de reconhecimento e fortalecimento do Turismo como campo acadêmico. Muitos pesquisadores em formação de mestrado e doutorado, vinculados ao então Laboratório de Tecnologia e Desenvolvimento Social da COPPE/UFRJ, participaram com afinco dos primeiros anos do periódico. Sem eles não teríamos chegado até aqui.

Ao longo dessas duas décadas, o CVT vivenciou diferentes ciclos e importantes transformações para garantir a eficiência de seus processos editoriais e a qualidade das pesquisas publicizadas. Implementamos o sistema de duplo parecer cego e para tal contamos com a mobilização de centenas de pesquisadores doutores de diferentes regiões do país. Empenhamos esforços para termos o reconhecimento de indexadores nacionais e internacionais e, mesmo com muitos obstáculos, conseguimos alcançar um patamar elevado em algumas das principais classificações.

Resgatando nosso objetivo inicial de sermos referência para publicação de pesquisas em Turismo no estado do Rio de Janeiro, o CVT estabeleceu no ciclo mais recente de mudanças novas parcerias com antigos parceiros. Pesquisadores que colaboraram em nossa caminhada foram convidados a representar suas instituições na ampliação de nossa equipe editorial. Assim, passamos a representar uma grande articulação interinstitucional envolvendo não apenas a UFRJ, mas também nossas coirmãs UNIRIO, UFF e UFRRJ.

A recomposição de nossa equipe editorial veio acompanhada de um novo delineamento quanto ao escopo da Revista. Em sua gênese, o CVT foi impulsionador de debates que priorizavam a interface turismo/ desenvolvimento social, com ênfase sobre o turismo de base comunitária. Nossa proposta aponta para um novo foco, sem que isso signifique abandonar nosso enraizamento originário. Nessa nova fase, direcionamos nossa atenção para debates, estudos, projetos e intervenções alinhadas com outra, não menos significativa, interface das práticas turísticas: a interface turismo/patrimônio.

Ao compartilharmos um pouco da nossa trajetória, celebramos as parcerias e encontros que tornaram possível nossa caminhada até aqui. Esperamos poder contar com seu apoio, leitor(a), autor(a), avaliador(a), pesquisador(a), para que os próximos anos sejam ainda mais profícuos.

Vida longa ao CVT! 